\title{
Mario Rapoport, Historia económica, política y social de la Argentina (1880-2003), Crítica, Buenos Aires, 2020
}

Ignacio Andrés Rossi*

Cuadernos de Historia. Serie economía y sociedad, N²6/27, 2021, pp. 437 a 442. RECIBIDO: 18/03/2021. EVALUADO: 01/06/2021. ACEPTADO: 15/06/2021.

La edición aumentada y corregida de este libro que apareció por primera vez en 2005, encuentra en la actualidad un momento más que oportuno para volver sobre su amplio análisis de la realidad argentina. Desde el apogeo del modelo agroexportador (18801914) hasta los avatares que en el siglo XX sacudieron la economía argentina, constituyen procesos ineludibles para pensar el futuro inmediato que nos depara ante los severos problemas socioeconómicos que está dejando la pandemia por COVID19. En este sentido, la historia, especialmente económica, tiene mucho que aportar al debate. Si bien el libro abarca un amplio conjunto de variables que involucran la coyuntura política y social en todos sus capítulos - las relaciones internacionales, el Estado, la población y las migraciones y el movimiento obrero -, en esta reseña nos centramos en comentar diferentes ejes que involucraron a la política económica argentina que, en definitiva, es el espíritu del libro y de la trayectoria del autor.

El primer capítulo se encuentra dedicado a analizar la etapa del modelo agroexportador argentino. En el presente, el apartado referido a la economía mundial se torna imprescindible para entender cómo y bajo qué condiciones la economía argentina se incorporaba a él. En aquellos años - bajo los difundidos principios del librecambio, en verdad algo agotados - la Segunda Revolución Industrial inglesa dio una respuesta a la

\footnotetext{
* Universidad Nacional de General Sarmiento. E mail: ignacio.a.rossi@gmail.com
} 
primera crisis del capitalismo (1873) acelerando la incorporación al mercado mundial de nuevos proveedores de materias primas como la Argentina, que incorporaba los beneficios de la inversión directa británica. Como dice Rapoport: aunque el Reino Unido en estos años veía declinar su productividad ante la competencia de Alemania y Francia, aquel seguía siendo tanto un gran exportador de capitales a través de empresas ferroviarias y préstamos gubernamentales como un actor político de relevancia dada la hegemonía del patrón oro, que le permitió a la Argentina - una vez lograda la paz social - integrarse al mercado mundial con intensas políticas de inmigración.

El segundo apartado abarca desde la Primera Guerra Mundial hasta la crisis de 1930, tornándose relevante la trayectoria de los gobiernos radicales en aquella época (19161928) y de cómo las estructuras del modelo agroexportador no se vieron alteradas con la primera contienda mundial. Rapoport destaca cómo a pesar de la caída del PBI que significó el inicio de la Primera Guerra y el descenso de las importaciones, la balanza comercial fue superavitaria, dando un amplio margen a las cuentas públicas. Aunque los efectos eran claramente negativos para la economía argentina, deben destacarse en estos años el desarrollo de una incipiente industria que serviría de base frente a los conflictos posteriores. Una vez finalizado el conflicto, se retomó la senda del crecimiento característica de los felices veintes debido a la masiva entrada de capitales y a los volúmenes de bienes exportados. Sin embargo, Rapoport matiza esto señalando los fuertes rasgos de vulnerabilidad: dependencia de la entrada de capitales, de la deuda externa y de la posibilidad de conservar mercados de exportación como de reducir el fuerte componente de importaciones que avanzaba.

En el capítulo tres, dedicado a la etapa de conflagraciones mundiales entre 1930-1945, el apartado sobre intervencionismo estatal permite analizar la evolución de la acción planificadora a partir de dichos conflictos. Puntualmente cómo a partir de la Primera Guerra la Argentina buscó preservar la vinculación política y económica con Gran Bretaña. Sin embargo, y con más agudeza en la crisis de 1930, Rapoport remarca que las elites liberales debieron implementar restricciones al comercio exterior y otras medidas heterodoxas para adaptarse a una coyuntura restrictiva. Estos fueron los años que el control de cambios e instituciones afines a cierto proteccionismo se volvieron una norma para la regulación de los mercados y poder hacer frente a las obligaciones 
financieras de la Nación y adquirir materias primas, combustibles y artículos indispensables para el consumo, entre otros.

En un capítulo sobre los gobiernos peronistas (1946-1955) Rapoport propone tres etapas diferenciadas de análisis. La primera, caracterizada por una etapa de auge (19451948) donde en la inmediata coyuntura de posguerra de incentivó un fuerte crecimiento del PBI, la producción, el consumo, la inversión y las importaciones. La política salarial y una progresiva redistribución del ingreso eran parte central de la alianza entre el Estado y la industria, aunque con una creciente participación del primero como incentivo del segundo y con el campo relegado a la provisión de divisas. En la segunda (1948-1952) se inició una etapa de depresión y tres años de virtual estancamiento combinado con el desplome de los precios internacionales, reducción de las divisas y un déficit de la balanza comercial haciendo evidente las débiles bases del modelo. Por consiguiente, en 1952 se implementó un plan de ajuste destinado esta vez a incentivar el campo, restringir el consumo, equilibrar las cuentas públicas e incentivar industrias específicas. El impacto positivo del plan logró retomar el sendero del crecimiento, aunque de forma más ralentizada, de manera que, como dice el autor, en su última etapa el peronismo estuvo lejos de constituir un caos económico como habitualmente señalan muchos estudios. Así es que Rapoport presenta evidencia empírica para cotejar que tanto la oferta y la demanda se encontraban en expansión, la inflación controlada, el comercio exterior en orden y un leve aumento del déficit fiscal, desmintiendo así las versiones que asocian la caída del peronismo a la crisis económica. En su quinto capítulo, que abarca desde la caída del peronismo en 1955 hasta 1966, Rapoport incluye un apartado sobre las corrientes económicas de la época. Así es que el autor identifica una heterogeneidad de proyectos económicos post caída de Perón, lo que contribuiría a que en el campo político se tradujera en cierta inestabilidad expresada en la volatilidad y el carácter coyuntural de las alianzas. De modo que en este capítulo el autor identifica cuatro gobiernos con una concepción económica diferente. Además, Rapoport destaca cómo las ideas keynesianas, a pesar de gozar de cierto predicamento, se bifurcaban en las particularidades históricas y regionales de diferentes proyectos de desarrollo. También el autor señala con agudeza histórica cómo irrumpían en la escena las ideas desarrollistas de Raúl Presbisch y Hans Singer, quienes desde la Comisión Económica para América Latina (CEPAL) y la 
Organización de las Naciones Unidas (ONU) ganaban impulsos y proponían modelos de desarrollo hacia afuera de corte industrialista con cierto proteccionismo. Por su parte, y como destaca Rapoport, la teoría neoclásica tampoco se mostraba homogénea en tanto una parte de la ortodoxia pregonaba el modelo de desarrollo hacia afuera de corte agrícola y sobre bases netamente liberales y otra se identificaba con las nuevas formaciones industriales ligadas al capital extranjero donde proponían vincular la economía nacional a las multinacionales.

El apartado sobre la política económica de la Revolución Argentina (1966-1973) en el capítulo enmarcado en los años de inestabilidad política (1966-1976) permite examinar las particularidades de militares gobernantes decididos a acotar la puja distributiva en detrimento de los asalariados y el sindicalismo, rompiendo así la alianza establecida por los populismos clásicos de los años cuarenta. Sin embargo, Rapoport precisa cómo el gobierno se preocupó por avanzar primero en la estabilidad política mediante represión para allanar luego el camino hacia lo económico. En cuanto a este último punto, se podría decir que un equipo económico heterogéneo, atravesado por disputas internas como un conflicto político y deterioro de las variables económicas implantaría un plan de estabilización heterodoxo con Adalbert Krieger Vasena. El autor puntualiza cómo, a pesar de sus medidas ortodoxas, fue novedoso en buscar una redistribución de recursos entre sectores económicos concretos.

Luego, en un capítulo sobre la última dictadura militar (1976-1983), Rapoport dedica un apartado completo al endeudamiento externo en aquellos años. Así, se examinan los inicios de una etapa de liquidez internacional que a partir del abultado déficit de la cuenta corriente estadounidense y los saldos comerciales positivos de los países de la Organización de Países Exportadores de Petróleo (OPEP), incentivaron la toma de créditos en países en desarrollo. Esto se conjugaría con los inicios de la dictadura argentina y el Plan de Martínez Hoz que liberalizó los movimientos de capitales, encaró una inédita apertura comercial y elevó las tasas de interés para incentivar las financierización. En este marco, el endeudamiento argentino atravesó una primera etapa entre el sector público y la banca internacional, pero en una segunda etapa Rapaport señala un nuevo enfoque que promovió el endeudamiento del empresariado privado a niveles inéditos en la historia argentina. En palabras del autor, estos sectores 
fueron altos funcionarios del gobierno, las fuerzas armadas, empresarios y financistas de grupos económicos nacionales y extranjeros y sectores primario-exportadores. El anteúltimo capítulo aborda el retorno democrático y el periodo neoliberal (19831989) tornándose importante el Plan Austral, que sería uno de los últimos ajustes heterodoxos de cara al consenso neoliberal de la década de 1990. El gobierno democrático de Alfonsín luego de intentar un programa keynesiano clásico con Bernardo Grinspun, fallido en un nuevo contexto de profundo endeudamiento e inercia inflacionaria, se dispuso a lanzar junto a Juan Sourrouille el Plan Austral. Rapoport describe cómo el ajuste positivo buscaba detener la inercia inflacionaria que amenazaba con la hiperinflación a la economía argentina mediante un congelamiento de los principales precios de la economía, la prohibición del financiamiento con emisión, una tabla de desagio para evitar la traslación de recursos de los contratos previos y el cambio del signo monetario. Según la evidencia presentada por el autor, este significó un ajuste más fuerte del que exigía el FMI en aquellos años y, a pesar de sus méritos en bajar la inflación significativamente, interpreta que quedó en el camino sin un programa de reformas económicas prescriptas.

Por último, Rapoport analiza la etapa de los años 1990 hasta la crisis económica del 2001 enmarcada en los problemas ya evidentes hacia fines de los años noventa y el inicio posterior de un nuevo ciclo económico y político a partir del 2003 con los Kirchner. Uno de los apartados más destacables lo constituye el dedicado a las interpretaciones de la crisis económica del 2001, conocida como la peor de la historia argentina. Allí el autor pasa revista de quiénes focalizan en los factores externos como las crisis de otros países o quiénes hacen hincapié en los efectos negativos de la globalización y en las políticas impuestas por las instituciones financieras. Aunque también destaca a quienes apuntaron a los factores internos como los altos niveles de endeudamiento, la política fiscal y las vulnerabilidades del sector externo, pero no cuestionaron las reformas neoliberales. Por último, se podría mencionar a quienes han entendido que la crisis fue resultante de las políticas neoliberales como las privatizaciones, la apertura económica y el endeudamiento externo o quienes entendieron desde un punto de vista histórico que el ciclo de financierización era un problema arrastrado por la Argentina desde la última dictadura militar. En suma, Rapoport se muestra crítico de la década de convertibilidad, que caracteriza como de 
"ilusión económica", y recupera una interpretación histórica de la crisis incluso más allá de la última dictadura.

La reedición de este libro aparece en un momento oportuno en que dar cuenta de los problemas económicos de la argentina se torna esencial para sortear la crisis que en nuestro país agudizara los problemas existentes desde hacía algunos años que se replicaban en la alta inflación como en la caída del PBI. Con su extenso estudio, Rapoport también demuestra que la historia se torna imprescindible para pensar y ensayar salidas que tengan en cuenta los factores históricos sociales y económicos de nuestro tiempo y también esto puede ser una guía para otros países de la región. 